\title{
The future of the Hungarian sour cherry growing branch
}

\author{
Apáti, F. \& Gonda, I. \\ Centre for Agricultural Sciences and Engineering, University of Debrecen 138 Böszörményi St., 4032 Debrecen, \\ Hungary
}

Summary: The present study deals with the actual situation of the Hungarian sour cherry production in order to outline the chances of the future and the trends of the development anticipated. The general conclusion accepted that on the long run Hungarian sour cherry production ought to be reorganised. The conditions of keeping the position on the international market are outlined: integration of small farms into large plantations (several times 10 hectares), introduction of mechanical harvest and high (15-20 t/ha) yields. For all that, adequate expertise should be developed on the cooperative farms, where the up to date technology could be applied with innovative initiatives. Small farms (up to 1-2 hectares) and home gardens have no chances to stay on the competitive market. The actual volume of sour cherry of 40-70 thousand tons per year cannot be increased in the future. The sour cherry area was 16000 ha in 2001, the actual is around 12-13 thousand, and will decline during the following 5 years to less than 10 thousand hectares.

Key words: Hungarian sour cherry production, sour cherry branch, competitiveness

\section{Introduction}

Sour cherry growing of the last years cannot be considered to be successful compared with other fruits. Producer's prices are far too low in relation to the costs of production. The poor demand did not justify risking the costs of harvesting let alone those of cultivation. Hundred and thousand grower succumbed to the disaster of the branch.

First we analyse the circumstances, then we attempt to explore the future. We have to remark that in our study dealing with the apple-growing branch, we treated on the horizontal level the conditions (organisation of the growers, guiding of the branch, research and development and extension service); therefore we confirm only the validity of those statements.

\section{The international and Hungarian status of sour cherry production}

The world's yearly contingent of sour cherry production amounted 1.1-1.3 million tons, $2 / 3$ part of it $(700-800$ thousand tons) is grown in Europe. Nearly 1/3 (300-400 thousand tons) in the European Union, which means that sour cherry of Europe, is decisive on the world market. The $70-80 \%$ of the yield produced by the EU is coming from three states: Poland (150-200 thousand tons), Hungary (40-70) and Germany (30-40), which means that Hungary is the second sour cherry producer country in the European Union. Important producers are Turkey (100-150) and Serbia (80-100), which are increasingly intruding into the European market, especially Serbia.
During the last decades, sour cherry yields varied around 40-70 thousand tons in Hungary, being about $6-8 \%$ of the fruits produced. No tendency could be stated, but a random seasonal variation. Considerable part of the yield (40-50\%) has been exported to Germany, partially as processed commodity. Thus export is a decisive contingent of utilisation.

Sour cherry consumption of the Hungarian population is rather low, $2-4 \mathrm{~kg} /$ year per capita, partially also processed. Demand of sour cherry for fresh consumption increased recently, Romania and other countries imported some quantity, but the handicap of further increment is the short ripening season of the fresh fruit (lasting 6-8 weeks).

\section{The technical level of Hungarian sour cherry production and the condition of plantations}

Statistical data of Hungary 2001 show about 16000 hectares sour cherries yielding 40-70 thousand tons. Mean yields are, consequently, 3-4 t/ha, which startlingly low. About half of the plantations being still young, no conclusions could be made, the other half considered to be fully yielding, may produce about twice of this amount, which is still insufficient. Further development of our sour cherry production means however difficulties because the basic conditions are extremely variable.

The age of plantations is characterised accordingly: $1 / 3$ of them is still young, less than 10-year-old, start yielding later. On the long run, higher yields would be expected, but meanwhile considerable areas are cleared because of the low 
producer's prises paid. The high rate of young plantations (approximately $10000 \mathrm{ha}$ ) is due to the favourable market conditions of the last decennium, when producer's prises approached 200-300 Ft/k. However, after 2004 - the low prices $(50-100 \mathrm{Ft} / \mathrm{kg})$ - the opposite tendency ensued, many plantations have been cleared.

The cultivation of the plantations could be described below based on estimations:

- it is supposed that several thousand hectares (about 3-4000 ha) are cleared already since 2001, the last statistical record.

- the rate neglected plantations is relatively high (about 4-6000 ha), which yield poorly (0-4 t/ha) and a low quality,

- the opposite extreme means the intensive cultivation, which is represented by maximum 1000-3000 hectares, and produce high yields $(8-12 \mathrm{t} / \mathrm{ha}$ as a mean of many years) and high quality,

- the rest of 4-6000 hectares represents a transition between the extremes with variable success.

Summarising the volume of sour cherry production in Hungary, 12-13 thousand hectares of plantations exists still since the statistical survey of 2001, when 16 thousand ha were estimated, and this tendency is continuing. Clearings are expected; plantings are negligible. The majority of plantations are obsolete; planting densities of more than the half of plantations is less than 400 trees/ha. More than $80 \%$ of the orchards are not irrigable, and only some per cent is watered. As a rootstock, Prunus mahaleb is dominant. The assortment is rather restricted, $90 \%$ of the yield is produced by 'Debreceni bőtermő', 'Újfehértói fürtös', 'Kántorjánosi' and 'Érdi bötermő', the first 3 of them are outstanding, in spite of that, they are ripe at the same time and appear on the market. The crown form, vase, is found on $1 / 3$ of the area being suitable only for mechanical harvest. Most of them are represented in young, up to date plantations.

\section{Conditions of the market and its peculiarities}

The current problems of the market are not bound basically to the character of a buyer's market but rather to the hectic changes of the market between years and sometimes within the same season being extremely variable and unpredictable. The main peculiarity of the sour cherry market is that of a fruit used mainly for industrial processing and only a small contingent (5-10\%) for fresh consumption. The bulk is sent to deep-freezing of to the processing industry (juice or canning). If marketing causes troubles, the type of utilisation, processing and fresh consumption cannot be distinguished clearly. Very often, the same goods are offered for both purposes. The causes of it are presented below:

- There are but a few growers, which produce exclusively or mainly for fresh consumption that means, production for processing dominate not only in the whole branch but also at every grower. Fresh consumption is a supplementary way of selling, a lucky episode for the grower.

- However, the price of sour cherry for processing influences the price of that for fresh consumption. The merchant interested in fresh consumption is bargaining easily when prices of processing sour cherry are low, there are no alternatives for the producer.

The hectic market is easily observed in Figure 1, where the prices paid by the processing industry are shown. Producer's prices vary on an extremely wide amplitude (400-500\%) during the last decennium. The variation is entirely unpredictable. The ambiguity of the future is an important handicap in planning an investment for a longer period. Thus, most serious problem of the branch is the instability of the market. The continuously low producer's price during the last years is another danger. The only exception was 2007, when the late frost reduced the yield to a minimum. The predictions of that period cannot guarantee the economical efficiency of sour cherry production.

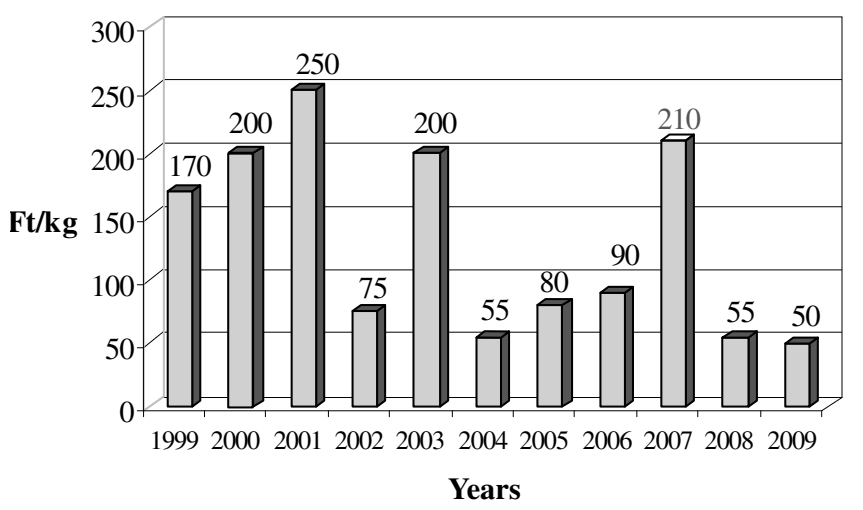

Source: original data collected in the Szatmári region

Figure 1: Variation of the producer's prices paid by the processing industry during the period 1999-2009.

The prices paid to the producer depend fundamentally on the relations between demands and offer. We have to remark that not only the home market should be regarded but also the European, in the case of sour cherry, which is concentrated to Poland, Germany eventually Serbia, where large volumes 3-4 or 5-6 times more than the Hungarian are produced and they determine the market relations. On the European market, Turkish and Iranian sour cherry will appear soon at higher frequency and will aggravate overproduction.

On the consumer's side, the demand seems to be invariable as seen in the respective statistics. The same is not rue in the case of the processing industry. The abundance of the previous year may reduce the demand of the currant year substantially. The variance of the supplies in the stores is far smaller than that of the yearly variance of yields in the successive years caused by weather and plant diseases (frost, hail, Monilia, etc.)

Summing up the relations explained, the stored supplies of the processing industry and the actual yields together are 
decisive in the variation of producer's prices. If both are high, prices are low (e.g. 2008 and 2009), low supplies and poor yields (2117) cause favourable prices. The picture changes from year to year and is unpredictable. As overproduction is generally experienced, prices will remain low with high probability.

An important component of the market is, of course, also the relations of strength between the participants: demand and offer (producer, merchant, processor, shopkeeper and consumer). The most potent of them is beyond doubt the detail dealer, and his effect is going backward until the producer's price along the path of the product. The chains of department stores decisively "dominate" the detail market. It means, commerce is much more concentrated than production. The producers represent the weakest bargaining position. It calls our attention on the importance of cooperatives of producers, which should be as strong i.e. large as possible. Some large, or even one large organisation for the country would be sufficient to secure a favourable deal compared with the host, several thousand, individual growers (in this relation, enterprises of several times 10 hectares are considered to be too small).

According to the information flow, not the intermediate dealers and processors are deciding the prices, but rather the chains of department stores as detail dealers, who meet the consumers. Their dominance is continuously increasing. An interesting contribution of a German businessman proves that the processing industry would be interested in higher producer's prices, which may allow larger price gaps and higher income. However!!! For the processor, the risk is lower when the fruit is cheap, because after some one or two years (when nobody may guess the marketing conditions) the sale would be more safe than of raw materials bought at higher prices.

The unpredictable and ambiguous situation of the market is observed not only between years, but also within 4-6 weeks of the same season (Figure 2). In every season, the starting prices are higher than the season's average, i.e. the early ripening varieties ('Pándy meggy', 'Cigánymeggy', 'Érdi bőtermő'). The bulk of the main varieties - 'Újfehértói fürtös', 'Kántorjánosi', 'Debreceni bőtermő', giving the

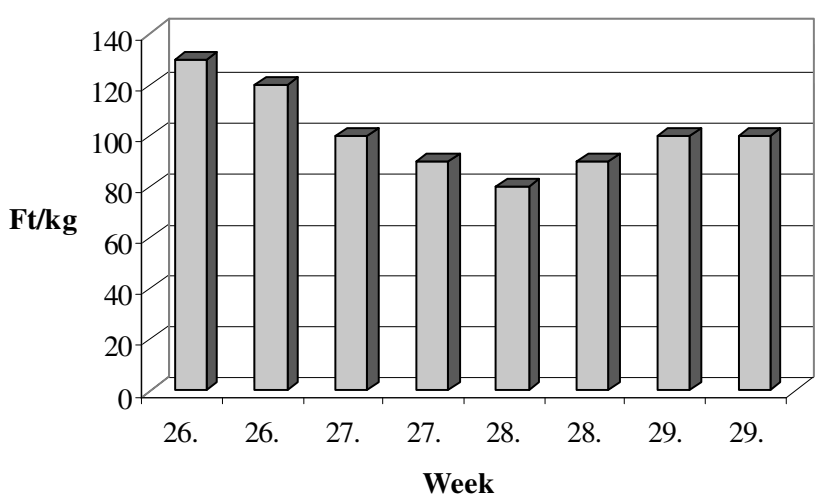

Source: original data collected in the Szatmári region

Figure 2: Changes of producer's prices paid by the processing industry in 2006 during the season (in half weekly intervals)
$60-70 \%$ of the Hungarian production - when harvested after 1-2 weeks, the market collapses, i.e. the prices fall by 40-60\%! (Figure 2).

The hectic changes within the season, the short sighted calculability and the chaos of the market may explained with three fundamental causes:

- the one-sidedness of the Hungarian assortment, as 60$70 \%$ of varieties are ripening at the same time, so a large volume is flooding the market,

- the attitude of the trade and the processors is striving to depress the producer's price according to its economical might,

- the endeavour of the growers to hurry with the harvest being afraid of the dropping prices; therefore sometimes unripe fruit of lower quality appears on the market and impairs the transport for export.

Here, we ought to remark that some growers of the SouthTransdanubian area, of Bács-Kiskun county and of South Hungary, where the harvest started earlier may succeed to get higher producer's prices than on the most important (30-40\%) NE-Hungarian (Szabolcs-Szatmár-Bereg county) region, where the majority of the volume is produced on the main varieties. At that time, the market collapses.

The trouble is aggravated by the fact that $40-50 \%$ of the Hungarian product is exported to Germany, where the market conditions influence decisively our prices because of their own sour cherry production, which is equally subject to variation. The lack of alternative markets delivers our prices to the ups and downs of German production. Sour cherry is particularly difficult to be stored; therefore the extension of the season by technical means is not possible, compared with apples.

German experts prove that several Hungarian merchants used to start bargaining in Hungary as well as in Germany weeks and months earlier than the harvest season to anticipate the possibilities of sour cherry export in Germany (meanwhile without disposing of goods), proposing insolently lower prices competitively, thus they start to reduce the producer's prices in advance. This deleterious attitude impairs not only the Hungarian but also the German growers by seeking their selfish advantage.

As a counterpart of the case mentioned above, the prices of the sour cherry for fresh consumption enjoy better conditions as shown in Figure 3, than that for processing. The variation is moderate and the sudden collapse of the market is less severe. The reason of it is its nature of a "gap market", the small quantity required by the consumers is safely furnished, but also some drop of the prices is evident at the appearance of the "bulk".

For Figure 3, we have to remark that the prices involve are not really producer's prices in spite of the designation of statistic estimates. The middlemen earn it, not the growers themselves on the wholesale market. ("the neppers"), who require a price gap of about 20-30\% (though any statistics are lacking to prove it), thus subtracting the turnover-tax we may calculate some $100-140 \mathrm{Ft} / \mathrm{kg}$, which is the income of 


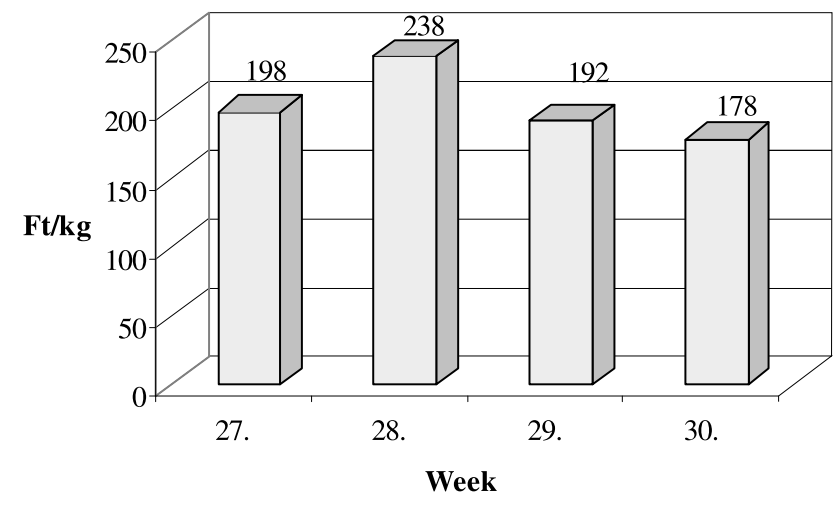

Source: AKI PÁIR

Figure 3: Consumer's prices of sour cherry for fresh consumption in weekly intervals in the season of 2006

the grower. The growers themselves attain the prices registered as far as they sell directly, but their rate within the society of growers is rather low.

\section{The profitability of growing sour cherry}

The production cost of sour cherry for processing wit manual harvesting is about $80-90 \mathrm{Ft} / \mathrm{kg}$ (Table 1). It is obvious that producer's prices of $50-90 \mathrm{Ft} / \mathrm{kg}$ do not secure any income for the grower. During the last 5 years two were loosing, two earned the production cost and only one year was profitable taking into account the harvesting costs only. The latter 2007, however, meant for the majority of growers a failure because of the total frost damage. In 2008 and 2009, the prices were as low as many growers did not harvest the fruit in order to avoid further losses. There was a period, when the producer's prices were less than $40 \mathrm{Ft} / \mathrm{kg}$.

Production costs for fresh consumption are higher than for processing of sour cherries (Table 1), because the manual harvest requires more care to maintain the stem and a selection for unhurt fruits, therefore the effectiveness is $60-70 \%$ compared with the fruits for processing. Depending

Table 1. Productions costs of $1 \mathrm{~kg}$ sour cherry for processing and for fresh consumption

\begin{tabular}{|l|c|c|c|c|}
\hline \multirow{2}{*}{\multicolumn{2}{c}{ The operation }} & \multicolumn{2}{|c|}{ For processing } & \multicolumn{2}{c|}{ For fresh consumption } \\
\cline { 2 - 5 } & $\begin{array}{c}\text { Cost* } \\
(\mathrm{Ft} / \mathrm{kg})\end{array}$ & $(\%)$ & $\begin{array}{c}\text { Cost* } \\
(\mathrm{Ft} / \mathrm{kg})\end{array}$ & $(\%)$ \\
\hline Pruning & 3.7 & 5 & 3.7 & 3 \\
\hline Tillage and cultivation & 1.3 & 2 & 1.3 & 1 \\
\hline Plant nutrition & 5.9 & 8 & 5.9 & $5-6$ \\
\hline Phytosanitary operations & 14.0 & 18 & 14.0 & $11-14$ \\
\hline Harvesting & 41.3 & 54 & 63.5 & $51-64$ \\
\hline Amortisation of the plantation & 9.9 & 13 & 9.9 & $8-10$ \\
\hline Packing & 0.0 & 0 & $0.0-25.0$ & $0-20$ \\
\hline IMMEDIATE COSTS & 76.1 & 100 & $98.3-123.3$ & 100 \\
\hline Indirect costs & 7.6 & & 7.6 & \\
\hline TOTAL PRODUCTION COSTS & 83.7 & & $105.9-130.9$ & \\
\hline
\end{tabular}

Source: original calculations

*Calculation anticipates a yield of $12 \mathrm{t} / \mathrm{ha}$ on the packing methods (cases, trays, etc.) the costs are variable on a wide scale. Altogether, the production costs for fresh consumption varies between 110 and $130 \mathrm{Ft} / \mathrm{kg}$. Consequently, we see that $100-140 \mathrm{Ft} / \mathrm{kg}$ as producer's prices are hardly securing a profitable income. We may remark that for fresh consumption, we cannot use mechanical harvesting, i.e. that type of reducing of production costs.

As a conclusion of the arguments we may state that during the last 5 years, sour cherry growing hardly secured profitable income neither in up to date, modern plantations. Growers are obliged to change their policy because the present conditions do not fulfil expectations neither of a modest type, because the competitive enterprises and the market conditions are deciding the prices and influence the marketing processes prohibiting a profitable production.

\section{Advantages and drawbacks of the Hungarian sour cherry management}

We would mention in advance that we explored and compared recently the management of Hungarian and German sour cherry growing enterprises. The choice of the countries is based on the above-mentioned relations that Germany is the most important export market of the Hungarian sour cherry, where about half of our yield is sold, therefore we are delivered to the tendencies, ups and downs of the German market. Germany is our main partner as well as competitor and the comparison will be instructive as both being participants of the same market and the mutual influence cannot be denied.

The advantages and drawbacks appear in a more suggestive form when paralleled. In our earlier study concerning "the future of our apple production", we compared already the production of the two countries. The same principles are valid for other fruit species too, but the relative weight of the individual components is variable. In relation of apple growing, we stated the following facts as being more advantageous in Hungary:

1. a good deal higher subventions of larger investments (for planting, storing and sorting capacities, mechanisation, etc.), which hardly exists but reduced in Germany,

2. Hungarian enterprises are not obliged to use anti-hail nets, which are rather expensive - as incidence of hails is less frequent,

3. manual labour is cheaper by $50-75 \%$ in Hungary, which means lower costs of production.

In this enumeration, point 1 is less important in sour cherry production, as planting of sour cherry is less expensive than of apple, and there is no need for expensive stores. Subvention of investments is less 
important for sour cherry growing. Hails are also less important source of damage than in apple growing, so the question of expensive nets is not actual as mentioned in point 2. The sole advantage of point 3 is an important factor of Hungarian sour cherry growing. The favourable cost of manual labour loose much of its advantage if mechanical harvest is applied. Summarising the arguments, we may state that the relative advantages of Hungarian sour cherry production loose their weight, when Hungarian manual harvest is compared with mechanical harvest in Germany. Moreover, the majority (60-80\%) of sour cherry harvesting is mechanised in Germany. Our chances in sour cherry production are on the same market rather equal, or perhaps the German growers enjoy some advantage with somewhat lower costs of production!

Our advantage in Hungary remains solely in the manually harvested sour cherry for fresh consumption. The advantageous difference in costs of manual labour will last certainly for more 5-10 years. The manually harvested processing type sour cherry is much less advantageous than for fresh consumption, which requires more manual labour due to the lower efficiency. However, contingents of this type of goods does not trespass the rate of $5-10 \%$ because shelf life (few days) as well as the season (6-8 weeks) of sour cherry are relatively short, and storing is essentially impossible. There are little chances of extending production, but the rate of fresh consumption still did not saturate the gap of market, which may offer a good issue for many enterprises.

A real handicap of Hungarian enterprises is the lower producer's prices $(20-30 \%)$ received compared with that of the German growers. The main reasons of it are:

- The Hungarian sour cherry is bound practically $(40-50 \%)$ to one sole market, and there are no alternative markets available. The strict dependence on conditions and prices of the German market is a clear drawback.

- The distribution of small enterprises and the insufficiency of cooperative bargaining on the market is an unequivocal handicap of the Hungarian fruitgrowing branch as the lack of cooperatives.

- Obsolete, neglected orchards and small plantation and home gardens represent a large contingent. Due to that, the market is puzzling, chaotic and cannot be organised and coordinated because the quality is poor and/or variable, which cannot be characterised uniformly as a condition of large scale bargaining.

- During the last years, Romanian and Russian merchant appeared on the Hungarian sour cherry market. It would be desirable to strengthen the tendency of finding alternative markets for Hungarian sour cherry.

\section{Outlooks and potentials of the future}

This chapter is aimed to suggest some changes in the management of the fruit-growing branch. First of all, growers producing on a high level are addressed - expected to continue the profession and keep their position on the market - in the plantations the mean yields should be maintained around 10-12 t/ha, and the producer's prices ought to be 120-150 Ft/kg at least as a condition of being profitable. The present prices (50-100 Ft/kg) are insufficient, but a 90-100 Ft/kg price - as a mean of years - would require 15-20 t/ha mean yields for being profitable, which is nearly or absolutely impossible. Nevertheless, if the prices remain invariable - which is expected regarding the prices of the last decennium - the raising yields is the only way of reduce the relative costs of production by applying technological tools (e.g. mechanical harvesting) as a condition of profitability.

It is beyond doubt that sour cherry growers ought to increase substantially their income, which is really very poor (if any). The existence of enterprises may have a thin time and on the long run they will give up. For increasing the income there are fundamentally three alternatives: increasing the producer's prices, increasing yields, and decreasing costs of production. Let us look on the possibilities.

\section{Increasing the producer's prices (?)}

We cannot find any argument allowing the hope that producer's prices will increase permanently in the future. German experts expressed the same (We should remark that the five year average of the producer's prices in Germany was $0.45 € / \mathrm{kg}$, the earlier five years produced more than $0.60 € / \mathrm{kg}$, whereas in 2009 it was $0.25-0.35 € / \mathrm{kg}$ ). The main cause of the drop was the extension of the EU to some eastern countries in 2004 with concurrent sour cherry growers. The strongest partner being Poland, where the manual labour is on the same price level or even lower than in Hungary, but their volume is 150-200 thousand tons, 3-4 times more than ours. The main cause of the low prices is the overproduction in Europe, which will be aggravated by the Serbian and Turkish import in the near future. Improvement in this sense cannot be expected neither on the long run.

A further counter-argument refuting the false hope of higher producer's prices is the nature of the market of horticultural crops. Prices are namely determined by demands and offers. The volume of goods and the strength as well as the position of the individual negotiators are decisive in bargaining. The rate of demand and offer changes continuously, so the prices vary and stable prices are not expected. This is true for the fruit markets especially for the sour cherry. The other fact is the producers' distribution against the concentrated and well-organised trade, which impairs the bargaining position of the producers. Practically, the lack of organisation dooms the individual grower to succumb to the conditions of the dealer and accept the proposed price without objection.

\section{How far yields are to be increased?}

As explained above, producer's prices will not increase neither significantly nor permanently, thus the problem ought to be approached from another side with lower risk. 
Calculations prove that at the present prices $(50-100 \mathrm{Ft} / \mathrm{kg}$ ) higher yields (10-12 t/ha) are required to attain profitability (i.e. to maintain some modest temporary liquidity), but far of being sufficient to secure development and reconstruction (clearing and to rejuvenate plantations). For that purpose we have to set the target of even higher yields, i.e. 15-20 t/ha!

\section{Diminish specific (prime) costs of production}

Profitability is hardly secured with relatively high (15-20 $\mathrm{t} /$ ha) yields, when prime costs remain invariable, thus costs of production ought to be reduced.

We have to emphasise that the prime costs are not understood on the surface basis (i.e. costs per hectares), but rather on the yield: costs/kg - not the suppression of some items of the production as a source of saving - but the realisation of the product with lower inputs. This target seems to be contradictory as it means that higher yields are depending on additional inputs (intensive technologies of higher level), but they facilitate higher yields if causing more income than the additional input. A suppression of interventions alone would lower the yields univocally and increase the costs of production.

The target is, in other words, to increase inputs in order to lower costs of production at same time. The only clear and valid possibility of reducing production costs is the application of mechanised harvest. (mechanisation alone does not influence the volume of yield, but reduces the costs of productions, substantially). It is beyond doubt that mechanisation should be introduced much more intensely in Hungarian sour cherry production. For that purpose, plantations are to be installed from the moment of planting design. The changes are not easily performed; the existing plantations are but hardly suitable for that purpose. The efficacy of the shakers depends on the following conditions:

- the fruits should be less susceptible to injury, detached dry from the stem and hard fleshed,

- size of the plantation should be larger than several times 10 hectares, where the use of a shaker is profitable,
- varieties of different ripening time ought to be chosen in order to extend the harvesting period evenly calculating for each period 5-7 days avoiding the danger of over-ripening, but each phase should be large enough to exploit the capacity of the shakers,

- the trunk should be high and the tree crown suitable for being shaken safely, where also the planting design and tilling system facilitates the movement of machines.

\section{Concluding statements}

To keep being on the market of sour cherry on the long run, the grower should manage a relatively large plantation (several 10 hectares), should harvest mechanically (subordinate everything for that purpose), attain 15-20 t/ha yields at least, applying high level technologies and outstanding expertise.

Small holdings (less than some 1-2 hectares) and home gardens will have little chances to maintain their existence, because mechanised harvest with their own machine is not profitable, hiring of that type of service is impracticable. Even more concern deserves the phytosanitary status of small plantations (Monilia, Blumeriella), which is prohibitive regarding high yields and adequate quality.

The past years and the anticipated near future (3-5 years) proves that the Hungarian sour cherry production will not attain 100-130 thousand tons yearly, being actually 40-70 thousand tons. Earlier, the favourable predictions between 1998 and 2001, when extremely high prices were paid, 6-8000 ha were planted. Those plantations arrived to produce full yields just now. The majority of those plantations became neglected because of the low producer's prices; moreover, many aged plantations were cleared since then. A further increment of the yearly 40-70 thousand tons is entirely improbable. In 2001, still 16000 hectares of sour cherry plantations existed, which were reduced to about 12-13000 ha, and subsequently to less than 10000 ha within the next 5 years. 